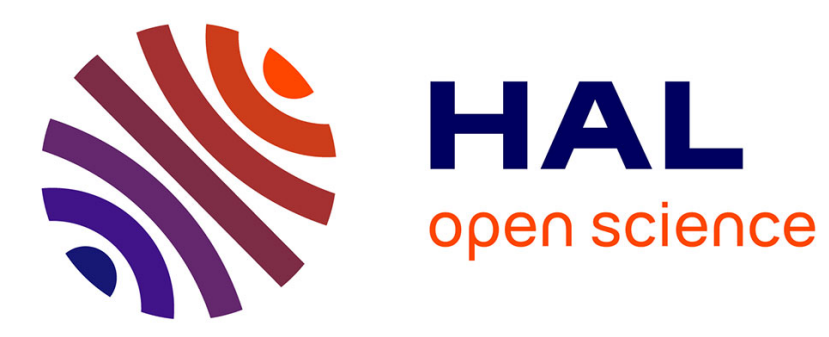

\title{
La contienda poética entre Juan de Valladolid, el Comendador Román y Antón de Montoro
}

Marithelma Costa

\section{To cite this version:}

Marithelma Costa. La contienda poética entre Juan de Valladolid, el Comendador Román y Antón de Montoro. Cahiers de linguistique hispanique médiévale, 2000, 23, pp.27-50. halshs-00186183

\section{HAL Id: halshs-00186183 \\ https://shs.hal.science/halshs-00186183}

Submitted on 8 Nov 2007

HAL is a multi-disciplinary open access archive for the deposit and dissemination of scientific research documents, whether they are published or not. The documents may come from teaching and research institutions in France or abroad, or from public or private research centers.
L'archive ouverte pluridisciplinaire HAL, est destinée au dépôt et à la diffusion de documents scientifiques de niveau recherche, publiés ou non, émanant des établissements d'enseignement et de recherche français ou étrangers, des laboratoires publics ou privés. 


\title{
LA CONTIENDA POETICA ENTRE JUAN DE VALLADOLID, EL COMENDADOR ROMAN Y ANTON DE MONTORO ${ }^{1}$
}

\author{
Marithelma Costa \\ Hunter College \& Graduate Center \\ City University of New York \\ (Cahiers de Linguistique Hispanique Medievales 23 (1999))
}

El siglo XV constituye uno de los periodos más desconocidos y fascinantes de la historia literaria española. Mientras el XVI se halla engalanado por los garcilasos de la vega, los san juanes de la cruz, los fray luises y las santa teresas; y el XVII se impone con los lopes, los góngoras y los quevedos, el XV se nos presenta como un páramo literario, como una especie de agujero negro en el que pocas cosas suceden. Por supuesto, como nos enseñan los especialistas en astro-física, el vacío nunca puede darse por completo. Existen tres excepciones: el Laberinto de Fortuna a mitad de siglo (demasiado extenso, demasiado farragoso y grandielocuente, en pocas palabras, un plomo); el Marqués de Santillana y sus fallidos sonetos; y las respetadas "Coplas a la muerte de su padre" de Jorge Manrique. Pero cuando cesamos de mirar la literatura a vuelo de pájaro y nos detenemos a analizar lo que se produjo durante esa centuria, de inmediato nos percatamos de que el periodo que va desde Imperial hasta el hijo de Rodrigo Manrique constituye una de las etapas más prolíficas de la poesía española. Estudiosos como Keith Whinnom y Alan Deyermond $^{2}$ calculan la existencia de más de 700 poetas entre 1370 y el siglo

${ }^{1}$ Leí una versión de este estudio en el Séminaire d'Etudes Médiévales Hispaniques auspiciado por la Université de Paris XIII el 17 de noviembre de 1997. Agradezco al profesor Georges Martin, director de dicho seminario y a sus participantes algunas de las ideas que se discutieron en el coloquio e incorporé en la redacción final de este artículo.

2 Keith Whinnom, La poesía amatoria de la época de los Reyes Católicos (Durham: 1981), p. 18; Alan Deyermond, "The interaction of courtly and popular elements in Medieval Spanish Literature", Court and Poet, G. S. Burgess, ed. (Liverpool: 1981), p. 25. 
XVI, y sitúan la mayor concentración de obras en las últimas décadas del siglo $\mathrm{XV}$, es decir, durante la época en que se lleva a cabo la polémica que trataremos en estas páginas. Por su parte, el Indice de autores de El Cancionero del siglo XV de Brian Dutton, ese monumento de los estudios literarios del cuatrocientos, se extiende por 149 páginas a columna doble y consigna alrededor de 640 versificadores.

Es cierto que no se trata de figuras mayores. Es verdad que la mayoría de estos autores no escribió demasiados poemas. Es indiscutible que muchos textos se parecen entre sí. Pero la impresionante cantidad de obras que se transciben y la preocupación de los compiladores por incluir el mayor número de escritores en sus cancioneros, nos permiten tener una idea de la importancia que adquiere la actividad poética en esa época en que la nobleza castellana se enfrenta tanto a la joven burguesía comercial como a la monarquía que va a acabar por imponérsele.

En este trabajo me centro en tres escritores de la época. Tres poetas menores que representan tres aspectos de esa realidad pluriforme y cambiante que es la sociedad del cuatrocientos. El primero, Juan de Valladolid, produjo muy pocos textos escritos, pero fue muy respetado en las cortes italianas y llevó la vida itinerante característica de los juglares del tardo medioevo. El segundo, el Comendador Román, estuvo al servicio del Duque de Alba, fungió como guardia personal de los Reyes Católicos y redactó un extenso poema religioso por mandado de los monarcas. Y el tercero, Antón de Montoro trabajaba de sastre o alfayate en la Córdoba preinquisitorial. Fue un reconocido converso que aunque entró en los palacios de los poderosos, siempre tuvo presente en sus textos su doble marginación social: el ser de origen judío y ganarse la vida como menestral.

A partir de 1455, estos tres personajes establecieron una recuesta o contienda poética, en la que intercambiaron un sinnúmero de versos insultantes. A primera vista esta justa literaria no se diferencia de las recuestas de la época. Los autores se valen de motes y apodos para subrayar su inaceptable origen étnico 
(judío o musulmán), su bajo nivel socioeconómico y su falta de pericia al escribir. ${ }^{3}$ Sin embargo, cuando estos poemas (en apariencia lúdicos y convencionales) se examinan de cerca, de inmediato salta a la vista que consituyen una valiosa fuente de información sobre la condición social y escritural de cada uno de los autores.

Pero comencemos por Antón de Montoro, el eje de la contienda. El poeta, a quien también se le conoce como el Ropero de Córdoba, nace con el siglo, vive durante los reinados de Juan II y Enrique IV, y muere entre 1483 y 1484 en la época de Isabel y Fernando, después que Sixto IV firmara la Bula de la Inquisición, y el Tribunal del Santo Oficio se instaurara en Córdoba. Los documentos que se conservan en las parroquias montoreñas y cordobesas no permiten afirmar dónde nació o fue bautizado; pero tanto en sus textos, como en los documentos notariales que se guardan en el Archivo de Protocolos de Córdoba, se confirma que ejerció el oficio de ropero (o aljabibe) y residió en las collaciones de San Andrés y Santo Domingo, conocidos barrios conversos de dicha ciudad.

No se sabe cómo accedió a la educación --vasta, refinada y cimentada en el manejo de los topos retóricos y la erudición alegórica-- que se requería para el cultivo del arte de la poetría. Y si se exceptúa el testamento que otorga en Córdoba en 1477 y los tres documentos notariales que lo mencionan y permiten ubicar la fecha de su muerte, de Antón de Montoro sólo han llegado hasta hoy sus poemas, es decir, los 164 textos de amor cortés, de elogio, de

${ }^{3}$ Monique de Lope ha puesto de relieve cómo muchos de los tópicos que se repiten en los motes y los apodos, remiten a la inaceptable condición de híbrido social del converso. Vid. "Sur un débat poétique entre Antón de Montoro et le Commandeur Román”. Ecrire à la fin du Moyen-Age. Le pouvoir et l'ecriture en Espagne et en Italie (1450-1530) (Provence: 1990), pp. 253-267 y "Les métaphores de l'identité conversa dans la poésie espagnole du XVe siècle", “Qu'un sang impur...". Les Conversos et le pouvoir en Espagne à la fin du moyen âge. Actes du 2ème colloque d'Aix-en-Provence 18-19-20 novembre 1994 . Jeanne Battesti Pelerin, coord. (Provence: 1997), pp. 109-121. 
burla y de negocios que conforman su obra poética. ${ }^{4}$ Por lo general se trata de poesía de circunstancias, composiciones que se hallan inscritas en los códigos léxicos, retóricos y genéricos de la lírica del cuatrocientos y que, a primera vista, no se diferencian de las de otros autores cortesanos. El poeta elogia a sus superiores, se burla de sus iguales y escribe textos tanto festivos como serios sobre los pormenores de la vida en los palacios andaluces.

Sus primeras composiciones datables se remontan a 1448, cuando redacta "Oh cama, de nuevos de ver girifaltes", un complejo poema de arte mayor donde denuncia a los responsables de la muerte de los dos hermanos comendadores. ${ }^{5}$ Los últimos poemas, también de tema político, son las tres extensas composiciones que produce entre 1473 y 1474 tras los motines anticonversos de Córdoba y Carmona en los que protesta ante Enrique IV, Isabel la Católica y Alfonso de Aguilar, por las persecuciones de que es víctima su grupo. ${ }^{6}$

Hacia la quinta década del siglo, el Ropero entabla su primera contienda literaria con Juan de Valladolid. Esta polémica --y sus ramificaciones-- me ha servido 1. para desentrañar al misterioso Juan de Valladolid, ese poeta nómada, querido y apreciado en las cortes de Italia, e injuriado y denostado en

\footnotetext{
4 Para la presentación y el análisis de la documentación en torno a Montoro, véase M. Costa y M. Nieto Cumplido, "Nuevos datos sobre la vida de Antón de Montoro, el Ropero de Córdoba”. Filología 1-2 . XXVIII (1996), pp. 33-45.

5 Para un análisis de éste y de otros textos poéticos de la época en los que figura el mismo tema, Vid. mi "Nuevas consideraciones sobre la muerte de los dos hermanos comendadores, la guerra cordobesa entre bandos y Antón de Montoro", La Torre V.20 (1991) 385-427.

6Poemas: "De más virtud que grandía", "Oh Ropero amargo y triste" y "De palabra verdadera". Todas las citas a la obra de Montoro remiten a mi edición anotada de su obra Antón de Montoro. Poesía completa (Cleveland: 1990). Para el resto de la poesía cancioneril, me baso en El cancionero del siglo XV de Brian Dutton (Salamanca: 1991), del cual utilizo tanto los textos como la nomenclatura, y en el Cancionero de poesías varias. Ms. no. 617 de la Biblioteca Real de Madrid preparado por J. Labrador, A. Zurita y R Di Franco (Madrid: 1986).
} 
las de Castilla; 2. para comprender mejor la obra de Antón de Montoro y algunas de las estrategias de sobrevivencia que utilizaron los conversos en la España preinquisitorial.

\section{JUAN DE VALLADOLID}

También conocido como Juan Poeta, Valladolid constituye una de las figuras más representativas de las cortes del cuatrocientos y uno de los poetas menores de origen converso sobre quien se cuenta con mayor número de documentos. Resulta significativo que todos ellos se producen en Italia, ya sea en las cortes meridionales de Alfonso y Fernando de Aragón, o en los palacios de los aristócratas italianos del norte de la península, dos ámbitos culturales mucho más propicios para los neocristianos que el suelo castellano. Este corpus documental se compone de siete actas notariales de la Cancelleria, dos de la Secrezia (ambas de Palermo) y cinco cartas de recomendación del rey Fernando de Aragón, el duque de Milán, la duquesa de Calabria, el marqués d'Este y el marqués de Mantua respectivamente. ${ }^{7}$ Según estos documentos -que hay que combinar con algunas fuentes literarias para hacerse una idea del periplo vital de Valladolid--, es posible demarcar cinco períodos en la vida del poeta.

PRIMERA EPOCA: PALERMO (c. 1422-1444)

Las nueve actas notariales que se guardan en el Archivio di Stato de Palermo describen el oficio, las obligaciones y el sueldo que el autor recibe por sus

7Para los documentos del Archivio Storico de Palermo, Vid. Ezio Levi, "Un juglar español en Sicilia (Juan de Valladolid)", Homenaje ofrecido a Menéndez Pidal (Madrid: 1925), III: pp. 435-439. 
labores en la aduana de la ciudad. ${ }^{8}$ En la primera, que se remonta al 5 de mayo de 1422, se establece su residencia en la ciudad de Alfonso el Magnánimo y el título que ostentaba: "scriptori et officiali in regia dohana". 9 En la última, fechada el 4 de julio de 1444 y firmada por el virrey, se menciona su oficio, se estipula el estipendio anual suplementario de catorce onzas que debe deducirse de las entradas de la aduana, y su nuevo título: "confector librorum dohana et secrezie". ${ }^{10}$ En efecto, a partir de 1444, además de consignar los movimientos de la aduana --labor que, según consta en el acta de 1422, se le permite relegar a una persona "suficiente e idónea"--, Valladolid es responsable de componer los libros que guardan los documentos personales de los reyes y los virreyes. Con el nuevo título aumentan sus responsabilidades y prestigio, ya que muchos de los volúmenes eran "libros mayores", quizás en pergamino y miniados:

magistros sunptuosos, elaboratos [...] quo modo ipsum pro exigentia et utilitate cabellarum predictarum -que in dies propterea incrementum evidens suscipiuntefficere et explanare oportet. ${ }^{11}$

8 Gómez Manrique alude indirectamente a dicho puesto pues describe la poesía de Valladolid como "trobas de almacén" en su poema LXXX "Si de vuestra detençión" (Cancionero, A. Paz y Meliá, ed. [Madrid 1885], II: pp. 118,). Sin embargo, Menéndez Pidal interpreta el mismo sintagma (que para Márquez Villanueva también remite a sus actividades en la aduana), como "poesía aprendida de memoria, acaso tradicional y, de cualquier modo, arcaizante", y lo utiliza para probar que Valladolid era un juglar reconocido (Ramón Menéndez Pidal, Poesía juglaresca y juglares [Madrid: 1924], p. 424; Francisco Márquez Villanueva, "Jewish 'Fools' of the Spanish Fifteenth Century", Hispanic Review 50: 1982, p. 399).

${ }^{9}$ Hay que recordar que el oficio de escribano no estaba reñido con el de poeta, y que Juan Alfonso de Baena también fungió de escribano de Juan II.

${ }^{10}$ La Secrezia del Alfonso el Magnánimo reunía los documentos personales de la familia real tales como las actas matrimoniales o de la propiedad, y tenía una función semejante a la del Archivio Segreto de las cortes pontificales (de Avignon y Roma), y la del Archivo Secreto de Toledo.

${ }^{11}$ Archivio di Stato di Palermo, Cancelleria, vol. LXXXIII, c 176r; Vid. Levi 1925, pp. 437438. 
A partir de este período el poeta abandona la estabilidad de su puesto oficial e inicia una vida itinerante por Castilla, Navarra y el norte de Italia.

\section{SEGUNDA EPOCA: CASTILLA (c. 1455)}

Según explica Menéndez Pidal en la edición de 1924 de Poesía juglaresca y juglares, Juan de Valladolid se halla en la corte de Juan II hacia 1453 (donde escribe sobre la desgracia de Alvaro de Luna), y quizás viaja a Córdoba en 1455 con el séquito del marqués de Villena, don Juan Pacheco, uno de sus protectores. ${ }^{12}$ Es probable que su justa poética con Montoro se iniciara durante ese viaje; pero como no existen documentos históricos que lo prueben, resulta imposible afirmarlo con seguridad. ${ }^{13}$ De haber comenzado en esa década, ésta se extiende a lo largo de veinte años e incluye el poema de primer verso "Noble reina de Castilla", que Montoro le dirige a Isabel la Católica.

12 De esta época, como de sus estadías subsiguientes en la península, sólo se tiene constancia a través de los textos que le dirigieron Montoro y otros poetas de la corte. Según el poema de primer verso "Syendo vos tan privado" de Gómez Manrique (Cancionero, II: pp. 114-115), el arzobispo de Toledo, Alfonso de Carrillo fue otro de los protectores de Valladolid. Y como consta en el epígrafe del poema de primer verso "Eres loco para frío" ("De Gómez Manrique a Mossén Juan, truhán del señor conde de Treviño, su hermano"), el polémico personaje también vivió en la casa de Pedro Manrique conocido como don Pedro II, conde de Treviño y primer duque de Nájera quien, según Serrano de Haro, fue "el más relevante Manrique de su generación”; Vid. Personalidad y destino de Jorge Manrique (Madrid: 1975), pp. 76, 95, 243.

13 Hay que recordar que las actitudes del Marqués de Villena nunca fueron especialmente filoconversas. Sus alianzas con don Alfonso de Aguilar pueden explicar tanto el reducido número de panegíricos que el Ropero le dedicó al noble cordobés, como el que el poeta estableciera una contienda literaria con Valladolid, un protegido suyo. 
Cabe señalar que dicha polémica cobra tal importancia que el mismo Gómez Manrique se suma a ella con un largo poema de ocho coplas reales dirigidas al Marqués de Villena "en nombre del Ropero" contra Juan de Valladolid. ${ }^{14}$

TERCERA EPOCA: FERRARA, MANTUA, MILAN (c. 1458-1462)

El 10 de octubre de 1458, Valladolid ha vuelto a Italia donde aparece en la corte del marqués Borso d'Este de Ferrara. ${ }^{15}$ La segunda colección de documentos históricos que ofrecen datos precisos sobre el autor se remonta a dicho periodo. Entre ellos se halla una carta de recomendación ${ }^{16}$ del mismo Borso d'Este a Francisco Sforza (quien ocho años antes se había autoproclamado duque de Milán), donde se identifica al poeta como 'Zuan de Vagliadolid, poeta ispano et vulgare secundo lui" [...] y se explica:

Et perchè luy dice essere huomo et cortegiano de la Maiestà del Re de Ragona et de Navarra etc. et anche pare che pur il sapia dir in rima.${ }^{17}$

\footnotetext{
14 Vid. Manrique, Cancionero, II: pp. 155-158. El escribir un poema en nombre de otro autor no constituye una anomalía en la época ya que Juan Alfonso de Baena pone en boca de Juan Marmolejo una fuerte invectiva contra Juan Agrás ("Poderoso dominable", en el Cancionero de obras de burlas provocantes a risa) y Villasandino compone su famoso decir "a manera de disfamaçión" contra "una dueña d'este reino, por manera de la afear e deshonrar, por ruego de un cavallero que gelo rogó muy afincadamente" que figura en el Cancionero de Baena. Para un análisis de las coplas de Manrique "en nombre del Ropero", Vid. Costa, "Las relaciones literarias de Antón de Montoro con los escritores y humanistas de su época", III Encuentros de Historia Local Alto Guadalquivir, Juan Aranda Doncel, coord. (Córdoba, 1991), pp. 147-161.

15 Giulio Bertoni, "Buffoni alla corte di Ferrara, Poesie, leggende, costumanze del medio evo (Modena: 1927), pp. 203-213; Levi 1925, p. 420.

16 La carta se guarda en el Archivio di Stato Milanese, Potenze estere: Mantova.

17 E. Motta, "Giovanni da Valladolid alle corti di Mantova e Milano", Archivio Storico Lombardo VIII-XVII (1890), p. 938.
} 
Esta última frase --"y aun parece que él sepa hablar en rima"-- hace pensar que existía una marcada diferencia entre el poeta --término que Valladolid utiliza para definirse y Borso d'Este repite citándolo--, y el improvisador, es decir, la persona que podía crear espontáneamente textos rimados. Juan Poeta viaja entonces a Mantua donde, según una segunda carta de recomendación a Francisco Sforza que le dirige el marqués de Mantua, Ludovico Gonzaga, ${ }^{18}$ ya se hace notar entre los enanos, bufones y cantores de palacio. El 22 de octubre de 1458, el Marqués escribe:

Lè stato qui cum meco alcuni zorni el portator presente, messer Zohanne, poeta vulgar spagnolo, el quale si per riverentia de la Maiestá del Re Fernando, del qual dice esser famiglio e servitore, si per le virtude sue e per la prompteza del dire improviso in rima ben in lingua spagnola, ho visto voluntera" (Motta 1890, p. 939). ${ }^{19}$

Evidentemente la situación ha variado, pues Gonzaga declara que ha sido testigo de la facilidad con la cual Valladolid crea sus improvisaciones rimadas en español.

Estas recomendaciones parece que surtieron efecto y Juan Poeta pasa entonces a radicarse en Milán como bufón. Según una tercera carta del mismo Francisco Sforza a la familia Gonzaga del 23 de enero de 1462, para esta fecha ya ha incorporado a sus destrezas de poeta e improvisador, otra actividad de los truhanes cortesanos: el conjurar, a través de hechizos, la caída del granizo. Esta vez el duque de Milán escribe: "Zovane Vaglidolit, spagnolo, exhibitore presente è stato qua et factomi dire como lui sa incantare la grandine". Como se

\footnotetext{
18 Esta segunda carta también se guarda en el Archivio di Stato Milanese, Potenze estere: Mantova.

${ }^{19}$ El término "voluntera" por 'volontieri' procede del dialecto romañol y ya figura en textos literarios del 1300 de Bolonia. Agradezco al profesor Giuseppe DiScipio esta información.
} 
trata de una corte plenamente renacentista, Sforza también afirma su afición por la forma poética en boga: "dice anchora luy essere poeta vulgare et molto delectarsi in soneti". Motta considera que Valladolid se hacía pasar por astrólogo, quizás prediciendo, a través de esta ciencia, las tormentas de granizo.

20 Sin embargo, Menéndez Pidal interpreta la frase sforzesca dentro del marco español y considera a Valladolid un "espantanublados", es decir, un personaje que antiguamente iba por los pueblos con hábitos largos pidiendo limosna y haciendo creer a la gente que tenía poder sobre las nubes. Aquí termina el segundo período italiano del autor y la mayoría de los datos históricos de que se dispone para reconstruir su vida.

CUARTA EPOCA: VALENCIA (c. 1470)

El Jueves Santo de 1470 el papa Pablo II concedió una indulgencia general (o perdonança) a todos los los peregrinos que asistieran a la catedral de Valencia. ${ }^{21}$ Según unas coplas de corte antisemita del Conde de Paredes, ese Viernes Santo, Juan de Valladolid se hallaba al umbral de la catedral haciendo que:

La bula del padre santo, dada por nuestra salud, metida so vuestro manto, se tornó con gran quebranto

${ }^{20} \mathrm{El}$ investigador italiano recuerda la importacia que tenía la ciencia de la astrología en la Italia del siglo XV, "favorita com'era dagli uomini colti, dai governi e dai principi più illuminati, nè considerata dalla Chiesa come infesta alla fede" (Motta 1890, p. 939).

21 Para mayor precisión cronológica, ese año el Jueves Santo cayó el 19 de abril. Según Kenneth Scholberg, éste constituyó "uno de los períodos de gracia durante los que los conversos o heréticos debían reconciliarse con la Iglesia" ( medieval [Madrid: 1971], p. 342, n. 67). 
escritura del talmud. ${ }^{22}$

Dado que esta fuente es puramente literaria, resulta imposible hacer ninguna afirmación adicional sobre su estadía en Valencia.

\section{QUINTA EPOCA: NAPOLES (c. 1473)}

Dos cartas de recomendación y un texto poético constituyen las fuentes del último período italiano del autor. En la primera, fechada en Nápoles en 1473, firmada por Fernando, rey de Aragón, y dirigida a los Gonzaga y a los Sforza, ya se alude a Valladolid como "assai caro" al rey y se le reconoce como "homo de singulare ingenio et de bona pratica cortesana". ${ }^{23} \mathrm{El}$ segundo documento es

22 En 11CG-969, fol. 222v; vid. Dutton, 1991, V, p. 514. Es muy difícil identificar al autor de este texto. Varios críticos piensan que pertenece al primer conde de Paredes, Rodrigo Manrique (Vid. Menéndez Pidal 1924, p. 478; Levi 1925, p. 422; José M. Azáceta, Cancionero de Ixar [Madrid: 1956], I: pp. li-lii; Scholberg 1971, p. 340 y Márquez Villanueva 1982, pp. 398-399). Por su parte, Cortina (en su edición del Cancionero de Jorge Manrique [Madrid: 1929, p. 247]) y Serrano de Haro (1975, pp. 51, 55, 78) señalan que se trata del hijo mayor de Rodrigo y segundo conde de Paredes, Pedro Manrique. M. Ciceri, quien también ha estudiado el caso, no se decide por ninguno de los dos nobles ("Lo smascheramento del 'converso' e I suoi stereotipi nei canzonieri spagnoli", Miscellanea di studi in onore di Aurelio Roncaglia [Modena: 1989], pp. 441-442).

Los códices no ayudan a res olver el problema, pues en el Cancionero de San Martino delle

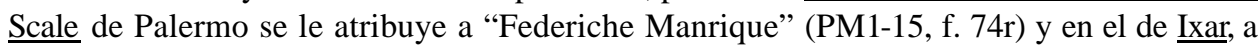
"Pedro Martynes" (MN6d-92, f. 338r). Para un interesante análisis de cómo la conversión se presenta en este poema a través de la retórica de la alteridad, Vid. Jeanne BattestiPelegrin, "A propos de la représentation du judéo-convers: le traitement burlesque de la conversion", Signes et marques du convers. (Espagne XVème siècles) (Provence: 1993) pp. 95-118.

23 Reproduzco la transcripción del documento que dio a conocer Bertoletti en Il Bibliofilo de Bolonia 6 [1886], p. 68. Agradezco a Carmen Sarasúa del Istituto Universitario Europeo 
otra carta (que se guarda en el Carteggio diplomático sforzesco) de la duquesa de Calabria, Ippolita Sforza, a su hermano Galeazzo Maria, el Moro, firmada en Nápoles, "Ex castro capuano" el 8 de junio del mismo año. ${ }^{24}$ En ésta, la duquesa recuerda los servicios prestados por el poeta a Francisco Sforza, padre de ambos:

Messere Zohan, poeta vulgare castiglyano, nanze la nostra partita da la patria, venne visitare la Illma. Segnoria del condam prencepo nostro padre, et fo da quella accarezato et donato secondo el suo costumo; hora por tal memoria vene fare reverentia a V. Illma. S.

de Fiésole y a Rita Mercuri de la Biblioteca Casanatense de Roma quienes me ayudaron a consultar esta rara publicación.

Ill.me. Marchio amice noster carissime

Lo exibitore del presente serrá Iean poeta homo de singolare ingenio et de bona pratica cortesana el, quale nui hauemo assai caro. Et de presente uene ad V.S. per uisitare quella qual pregamo che per nostra singolare conplacentia lo uoglia hauere per recomandato del che ne fara conplacentia grandissima.

Dat. in castello nostro nouo Neapoli viiij Junij. MCCCCLXXIII.

Rex Ferd.

Ill.mo. viro Lodovico

de Gonzaga Marchioni

Mantue amico nostro

carissimo

${ }^{24}$ Cartella n. 387; Vid. Motta 1890, p. 940. 
Las "Coplas de Ribera a Juan Poeta estando los dos en Nápoles" 25 se sitúan en este quinto período del poeta y resumen la contienda tripartita en cuyos ejes se hallan Valladolid, el Comendador Román y Antón de Montoro. ${ }^{26}$

De estos documentos resulta evidente que Juan Poeta fue conocido y apreciado en las cortes italianas donde, después de trabajar de escribano y librero --y quizás hasta de restaurador de los steri o paneles de la gran sala de los hositales reales--, ${ }^{27}$ se convierte en un reconocido improvisador y hasta es considerado por Fernando, rey de Aragón, como un hombre de "singular ingenio y buena práctica cortesana". Pero a pesar de ello, el número de textos suyos que ha

25 “O, que nueuas de Castilla"(11CG-1003, fol. 229r) tuvo bastante éxito en el siglo XVI pues se reimprime en esta antología hasta 1535 y también aparece en el Cancionero de obras de burla (19COB) de 1519.

Menéndez y Pelayo (Antología de poetas líricos castellanos [Madrid: 1944], II: p. 279) no se atreve adscribir el texto a Juan Ribera (como figura en el epígrafe de19COB) ni a Suero de Ribera (a quien se lo adjudica Battesti-Pellegrin ["Les poetes convers et le poivoir: le débat poétique entre Gómez Manrique et Juan de Valladolid", Ecrire à la fin du MoyenAge. Le pouvoir et l'écriture en Espagne et en Italie (1450-1530), Provence: 1990, p. 250]), ya que la parca información que proporciona el epígrafe de Hernando del Castillo resulta insuficiente para determinar quién lo escribió. Por su parte, Dutton consigna otro texto de Ribera "a un truhan". Se trata de la copla castellana de primer verso "De dos cosas me acuerdo", donde Ribera moteja a otro personaje por ser pésimo poeta y peor albardán: "queres cuerdo para loco / y loco para trobar" (11CG-990, fol. 226v; Dutton, 1991, V: p. 522).

${ }^{26} \mathrm{El}$ poema menciona tanto al Ropero ("esse ombre muy famoso / poeta muy copioso / llamado anton de montoro"), como al Comendador ("Especialmente roman / contra vos lleno de enojos / que os llama ganapán”). Es probable que el término post quem de su composición sea 1478, año de la firma de la Bula de la Inquisición ya que Ribera alude a las quemas de judaizantes en conexión con algún tipo de autoridad: "Han quemado un nieto mío /que por su causa me pesa / que tienen su mujer presa / y dizen ques él judío". Hay que recordar que la Bula del Tribunal del Santo Oficio data del 1 de noviembre de 1478 y que el primer auto de fe se llevó a cabo en Sevilla, el 6 de febrero de 1481 (Henry C. Lea Historia de la Inquisición española [Madrid: 1983], I: pp. 185, 189).

${ }^{27}$ Levi 1925, p. 26. 
sobrevivido es muy reducido. Se trata de dos poemas dirigidos a Alvaro de Luna: "Condestable esclarecido" e "In Dey nomini por quanto" (o el "Testamento del Maestre de Santiago" también atribuido a Fernando de la Torre); dos canciones a la Infanta María (hija de Juan II de Navarra y hermana de Fernando el Católico): "No veros mes osadía" y "Exçelente gentil dama" 28 y un intercambio poético con Gómez Manrique ${ }^{29}$ y dos con Antón de Montoro.

Frente a esta reducida producción literaria, se tiene constancia de que este fascinante personaje recibió ocho invectivas de Gómez Manrique, ${ }^{30}$ seis de Montoro, dos del conde de Paredes, y otras dos del Comendador Román y Ribera respectivamente. ${ }^{31}$ En el 11CG hay tres poemas adicionales en su contra: uno de un galán y los otros, de dos escuderos. ${ }^{32}$ Es imposible identificar a sus autores, quienes coinciden en motejar a Valladolid por su origen judío. No ha sobrevivido ningun a respuesta del poeta a dichos textos.

Esta serie de datos apunta a que, a pesar de ser conocido como Juan Poeta (así figura en las rúbricas y los textos que se le dirigen), más que poeta

${ }^{28}$ Estas dos composiciones son anteriores a 1466, año en que la Infanta sale de Navarra, casada con Guillermo de Monferrato (E. Cotarelo y Mori, Cancionero de Antón de Montoro [Madrid: 1900], p. 342).

29 Para un análisis de "El loaros syn mudança" (que, según el epígrafe, Juan Poeta envía a Gómez Manrique desde Aragón), donde se explora el deseo del poeta de establecer una ruptura con la comunidad judía, Vid. Michel Jonin, "Quand les poètes nouveaux chrétiens content leurs exploits cynégétiques”, Signes et marques, 1993, pp. 63-76.

30 Poemas LXXVII, LXXVIII, LXXXIX, LXXX, LXXXV, XCI, XCII y CV, Cancionero 1885, II: pp. 116-120, 141-144 y 155-160 y 227-229.

31 Román le dirige "Don Poeta, desflorado", pero el copista se equivoca e identifica a Montoro como destinatario del poema.

32 "Este sayo os envio", "No os pesara, Juan hermano" y "Por me haber importunado" (11CG-1028, 1031 y 1032, fol. 234r, Dutton, 1991, V: p. 537). 
Valladolid fue un versificador ambulante, es decir un juglar que anduvo de corte en corte ofreciendo sus servicios a los aristócratas que supieran valorarlos. ${ }^{33}$ Como hombre de "buena práctica cortesana", conocía las reglas de la gaya ciencia (condición imprescindible para todo aquél que se moviera en las cortes de la época) y cuando era necesario podía componer panegíricos, canciones de amor cortés y respuestas por consonantes a los textos que le dirigían los poetas de palacio. Su verdadero talento, sin embargo, giraba en torno a la oralidad y la improvisación, y no a la producción escrita de coplas y decires.

Pero entremos en la recuesta. El primer poema de Valladolid "Podéis llamarme enemigo", quizás se remonta a su viaje a Córdoba de 1455 y constituye una réplica a "Juan, señor y grande amigo" de Montoro. En el segundo, "Hombre de poca familia" (que se inscribe en la séptima década del siglo) el poeta responde a "Noble reina de Castilla", donde Montoro le acusa de ladrón ante Isabel la Católica. Estos cuatro poemas se completan con "Acá non sé de qué villa", contrarréplica del Ropero al segundo texto de Valladolid. No se tiene constancia de las posibles reacciones de Juan Poeta a "Templo de rica famila" (que el Ropero dirige al Cabildo de los Abades de Córdoba para evitar que apoyen económicamente a su adversario), ni a "Mucho quisiera loar", de Montoro al arzobispo de Sevilla.

Como sucede en el subgénero de las recuestas, los ataques de ambos autores reproducen los tópicos de la poesía de vituperio medieval. ${ }^{34}$ Pero cuando se analiza la serie, resalta el cambio de modalidad retórica entre el texto del Ropero que inicia la justa, y las réplicas de Valladolid. En el primer poema

33SSegún Menéndez Pidal, los constantes ataques de que es víctima se parecen mucho a los denuestos que caían sobre los juglares gallegos cuando "se subían a trobadores" (1924, p. 426).

34 Para una útil clasificación de la poesía de escarnio y maldecir, antecesora directa de estas recuestas, Vid. M. Martins, A sátira na literatura medieval portuguesa (Lisboa: 1986), pp. 41-47 y 62-95. 
"Juan, señor y grande amigo", Montoro le recuerda a Valladolid que ambos son conversos:

Juan, señor y grande amigo, con mi corazón muy sano, vos quiero dar un castigo, tomadlo como lo digo, como de padre o de hermano: siquiera por los gentíos daquellos tribos muy nuestros, por ser yo y vos judíos, vuestros enojos son míos y mis daños todos vuestros.

El Ropero asimismo lo recrimina por su poca pericia al escribir:

vos facéis unos sermones, unas coplas sin brahones que non tienen sal nin agua.

Como era común en el género, el poeta también recurre a los motes de linaje, declara el oficio del padre de su contrincante y le sugiere que siga sus pasos y se haga pregonero:

vuestro padre gran cabida

que, non vos querrá faltar en el pregón de medida, que vos lo renuncie en vida do ternéis un pie daltar.

El tono de estos ataques resulta sumamente moderado: en el primero se establece la existencia de un estigma compartido, el segundo se centra en el 
tópico del menoscabo profesional de Valladolid y el tercero toma la forma de un irónico consejo.

A pesar de la mesura del original, Juan Poeta le responde al Ropero con una agresiva invectiva $\mathrm{y}$, en "Podéis llamarme enemigo", interpela a Montoro a través de motes descubiertos ("redondo como bodigo", seso "de avellano") y motes de linaje ("confeso marrano", "judío del ginetal"). Las tibias alusiones al judaísmo compartido --algo que Montoro presentaba en tono irónico y solidario--, se convierten en un arma a través de la cual Valladolid subraya la inaceptable condición de híbrido social y religioso de su interlocutor. El poeta no limita sus ataques a la persona del Ropero, sino que los extiende a su familia:

Vuestra madre, con fornicio,

andovo facer revenga, caliente, fuera de quicio, razón es, sin más bollicio, que por herencia vos venga,

a su pericia artística ("vuestra ciencia de can") y a su oficio de sastre remendón:

seso de loco sin par, aquel pregón por fenida

me dará mijor comida, que non a vos el remendar.

El Ropero abandona entonces el ámbito de la ironía y en "Templo de rica familia" se dedica a desacreditar abiertamente a su rival. Además de motejarlo por su linaje ("Pues, ¿sabéis quién es su padre? / Un verdugo y pregonero"), lo acusa de ladrón ("que con un solo cantar / cala todas Españas"). Este cargo también lo repite en "Mucho quisiera loar" copla que dirige al arzobispo de Sevilla. El Ropero se vale aquí del lenguaje procaz y directo que caracteriza la temprana recuesta de Baena y Villasandino (la madre de Valladolid es "criada de un mesonero" y "a las puertas del establo, / nunca da paja sin coño"). 
Asimismo el autor recrea un dramático diálogo entre el padre del poeta (quien se halla en total estado de embriaguez) y su tabernero:

Su padre, de pie y de pierna, sin camisa y desbrochado;

es su cama la taberna, su lonja, el mal cocinado.

Su mayor proheza y fe es: -A daca mi terrazo;

-Si pagastes, -Non pagué;

traque, danle buen jarrazo.

Antes de pasar a la obra del Comendador Román, resulta necesario reenfocar la figura de Valladolid y considerarlo una mezcla de versificador y declamador de textos literarios; es decir, un personaje que se movía en los ámbitos de la recitación, la improvisación y la oralidad. El mismo uso del término poeta como apelativo podría apuntar a una falta de consenso sobre su propia condición de escritor. Más que al oficio del poeta --o el individuo que se maneja dentro de la palabra escrita (figura que se estaba imponiendo en la sociedad del cuatrocientos)--, Juan de Valladolid se vinculaba a la "vocalidad" medieval, concepto que, según Paul Zumthor, aglutina varios modos de la voz memorizada, improvisada y leída. La definición que Menéndez Pidal da de los juglares puede resultar sumamente útil y esclarecedora para describir su labor: "juglares eran todos los que se ganaban la vida actuando ante un público, para recrearle con la música, o con la literatura, o con charlatanería, o con juegos de mano, de acrobatismo, de mímica". ${ }^{35}$

En efecto, Juan de Valladolid fue uno de los últimos juglares del medioevo, y su nomadismo vital constituye un signo de esa época en que toda Europa se vio afectada por la migración giratoria y permanente de estos personajes. Hoy en

35 Menéndez Pidal, 1924, p 12. 
día su figura sería parangonable a la del "performer", esa combinación de actor y animador, que crea y recrea textos con la ayuda de la voz, los gestos y los ademanes; y cuya primera lealtad radica en su público, a quien debe entretener, variando --y hasta traicionando-- su texto original. Esos espectadores deseosos de divertirse son los que maneja en Italia (sin duda con la ayuda de sus veinte años palermitanos). Se trata de un público napolitano, milanés, ferrarense y mantuano que se dejaba llevar --y hechizar-- con sus destrezas de versificador, improvisador y hasta de encantador de granizo.

Sin embargo, cuando vuelve a España (país donde se estaba imponiendo la obsesión por la limpieza de sangre), su procedencía judía eclipsó todas sus habilidades. Al llegar a este punto se hace difícil no proponer dos ideas adicionales que pueden redondear esta hipótesis. La falta de éxito al regresar a su tierra también pudo deberse a que sus años en Sicilia y en las cortes del norte de la península itálica, habían hecho de Valladolid un cortesano "a la italiana" y lo habían desviado de los gustos netamente castellanos. En efecto, el residir tanto tiempo en el extranjero alejó sicológicamente a "Zuan de Vagliadolid" de sus coterráneos, con los cuales, a su retorno, sólo lograba relacionarse a través de su condición étnica y cultural.

Por otro lado, al no poderse afiliar cabalmente a ninguna corte señorial castellana, el polémico Juan Poeta experimentó la otra cara de la juglaría y vivió en carne propia los efectos que la extensión y empleo de la escritura, la aparición de la figura del poeta letrado (con el poder del libro que lo respaldaba y la estabilidad de su oficio) y el lento derrumbamiento de las estructuras feudales, estaban teniendo sobre el prestigio de los recitadores, cantores y cuentistas quienes, de portavoces de la sociedad medieval, estaban a punto de convertirse en una especie de proletariado cultural. ${ }^{36} \mathrm{El}$ centrar su oficio en el de improvisador de textos rimados y declamador, ayuda a justificar el contraste entre el reducido número de composiciones suyas y el que hubiera sido

${ }^{36}$ Paul Zumthor, "Poésie et théâtralité. L'example du Moyen Age", Le théatre et la cité dans l'Europe médiévale (Stuttgart: 1989), pp 74-77. 
seleccionado como destinatario de veintiún poemas vejatorios. Valladolid ocupó así una posición relevante entre los versificadores de su época, pero no porque perteneciera a la palabra escrita, sino al mundo de la representación oral.

\section{EL COMENDADOR ROMAN}

Montoro estableció una segunda diatriba poética con el Comendador Román. Frente a la desigualdad numérica de los poemas que intercambió con Valladolid (6 del Ropero y 2 del poeta-juglar), su recuesta con el Comendador, se divide en dos fases y se caracteriza por un relativo equilibrio de los textos ( 7 de Montoro y 5 de Román), ${ }^{37}$ por una alusión intertextual a la recuesta con Valladolid y por un largo poema donde Román recrea los rituales religiosos y costumbres culturales de los judíos.

En sus ataques ambos autores utilizan los típicos motes de linaje (alusiones al judaísmo de Montoro y al arabismo de Román) y los clásicos insultos de ladrón y de mal escritor. Sin embargo, en "Antón parias sin arrisco" Román se excede hasta tal punto en su invectiva, que Montoro aparentemente acepta su derrota y compone "Por vuestras letras pasé" para establecer la paz con Román. La condición de juego literario del intercambio poético se hace evidente, pues en este fascinante texto Montoro manifesta la superioridad de su rival $\mathrm{y}$, con su fingida retirada, parece declararlo vencedor en la justa. Sin embargo, como

37 Primera vuelta: Montoro: "Hombre de muy buen consejo", Román: "Con pura malenconía"; Montoro: "Pobre de sabiduría; Román: "Antón parias sin arrisco"; Montoro pidiendo la paz: "Por vuestras letras pasé".

Segunda vuelta, Román establece un nuevo desafío: "RecordAntón que dormís"; Montoro: "Pecador, dellos venís"; Román: "Las trobas que vos hacé” y "Hombre de muy malas gatas"; Montoro: "Malo con quien a Dios pesa” y “Cuál es hoy el caballero?”; último poema de Montoro a Puertocarrero sobre Román: "Honestísimo galán". 
veremos más adelante, la capitulación es sólo aparente, el Comendador desafía de nuevo al Ropero y se inicia una segunda fase en la recuesta.

Aunque Montoro pudo haber intercambiado motes con Román y Valladolid durante la misma época, ${ }^{38}$ su relación con Juan Poeta se inicia antes de la que mantuvo con el Comendador ya que este último alude a ella en un interesante ejemplo de intertextualidad del cuatrocientos: "yo [...]no Juan de Valladolid, I mas para vos [soy] el diablo". Al igual que en aquél, en este intercambio poético se incluye un texto a un tercer personaje (de Montoro a Puertocarrero) donde el Ropero declara abiertamente cuán despreciable le resulta la obra del Comendador.

Estas dos recuestas ofrecen perspectivas complementarias sobre el inusitado pasatiempo cortesano. Si al enfrentarse con Juan de Valladolid, Montoro se mide con un conocido improvisador, capaz de responder por consonantes a sus epigramas; pero que no se distingue por su prestigio como poeta, ni por su posición social; al retar al Comendador se topa con el contrincante de amplio aliento poético y clase social aventajada que puede superarlo. Montoro reconoce y expresa su vulnerabilidad ante Román de dos maneras. Por una parte, en su primer texto establece (e intenta mantener) la diatriba en el ámbito de la ironía (plano menos arriesgado que el de los crudos motes de la invectiva). Pero al igual que Valladolid, el Comendador no acepta dicho nivel retórico y desde el principio recurre a la agresión frontal. En vista del fracaso, el Ropero cambia de estrategia y aparentemente le concede la victoria a su contrincante. Sin embargo Román tampoco le permite retirarse de la contienda, lo desafía de nuevo y Montoro se ve obligado a continuar el enfrentamiento verbal.

38Para Cotarelo (1900, pp. xii-xiii) la querella pudo iniciarse hacia 1455, durante el viaje a Córdoba del Duque de Alba (protector de Román) a las bodas de Enrique IV. Por su parte, Monique de Lope prefiere situarla en un marco menos específico, y la vincula a uno de los varios desplazamientos militares a Córdoba que llevó a cabo el Duque de Alba ("Sur un débat poétique entre Antón de Montoro et le Commandeur Román”, Ecrire à la fin du Moyen-Age, p. 254). 
Hasta ahora, esta actitud tan poco beligerante por parte de Montoro resultaba difícil de explicar en un autor que se distingue por su manejo de las técnicas de la sátira y la burla. De Román no existía ningún documento histórico que ayudara a aclarar estas posturas. Se pensaba que, como confiesa en "Nunca fue pena mayor" (su glosa a una canción del duque de Alba), entre 1465 y 1474 había estado al servicio de dicho personaje. ${ }^{39}$ Aparte de este texto, cuyo estudio resulta de sumo interés dada la cantidad de información anecdótica que el autor incorpora en sus versos, también se conocía "Vos mi dios por mi tristura", irónica recuesta con "su amiga por que le dixo que se fuesse para feo" 40 su poema elegíaco al príncipe don Juan (el heredero de los Reyes Católicos que muere en 1498), las tres preguntas y respuestas que intercambia con un poeta llamado Romero, y su extenso poema religioso, escrito por encargo de los Reyes Católicos, las Trobas de la pasión, continuadas en las Coplas de la pasión con la resurrección.

Sin embargo, en su edición de dichas Coplas, Giuseppe Mazzocchi identifica al misterioso Comendador como Diego Román, vecino de Toledo, y quien se menciona en tres importantes documentos. El primero es una carta de perdón a su favor por la muerte de Juan de Luzón, que la Reina Católica firma en Palencia el 27 de septiembre de 1475. El segundo es otra carta, fechada el 12 de mayo de 1493, donde los Reyes Católicos ordenan que se recoja información sobre una heredad suya ubicada en Toledo, en el término de la

39 En sus versos 14 y 15 escribe: "famoso franco sabido / duque dalua mi señor", 11CG2481 fol. 112v, Dutton, 1991, V: p. 286.

40Giuseppe Mazzocchi ("Poesía amorosa del comendador Román", Ecrire à la fin du Moyen-Age, pp. 43-77) presenta un excelente análisis retórico y una muy completa anotación de este texto. El crítico italiano señala la estructura antitética, el uso de elementos cromáticos y el origen de los materiales lingüísticos de las doce coplas. Este último punto resulta fascinante ya que en la recuesta se combina el estilo alto de la convención poética del amor cortés --en las coplas dedicadas a ensalzar a la dama--, con la lengua de la tradición "d'escarnho e maldizer" --en las coplas que reserva para aludir a su propia persona. El Comendador también se vale de este segundo registro lingüístico y estilístico en su contienda con Montoro. 
Bastida. El tercero, es un albalá del 15 de mayo de 1493, firmado por Isabel, donde se establece "de quitación en cada un año veinte mil maravedís" por su labor de "contino de mi casa". ${ }^{41}$ Los últimos documentos (redactados a dos días de distancia) identifican a Román como contino o guarda personal de los monarcas, con lo que Montoro ya no se halla frente a un poeta que jamás llegó a los círculos de poder castellanos (como el converso Valladolid), sino con alguien muy cercano a la corona.

Pero una vez más, vayamos a la justa poética. La primera vuelta se inicia cuando Román envía al Ropero un poema que le ha escrito a una dama para pedirle su opinión. Aunque no se tiene constancia de qué texto se trate (quizás fuera el poema a su amiga "Vos mi dios, mi tristura" ya mencionado, quizás una composición que se ha perdido), el Ropero le responde con "Hombre de muy buen consejo", una irónica composición donde pone en duda el saber poético de Román y añade su acusación favorita: la copla es robada.

Hombre de muy buen consejo

estas trobas, no con riña, llenan tal el aparejo, cual las fizo mogro viejo a Ysabela Cabtiña.

Nuevas son las invenciones, ellas sobran a las buenas, mas, por Dios y sus razones, nos cisméis los corazones: publicadlas por ajenas y guardaos de las setenas.

Según Monique de Lope, a lo largo de este poema, que se desarrolla en la tradición retórica de la "gracia", Montoro muestra gran respeto por las reglas 
cortesanas del recuestar tal y como las codifica Hernando de Ludueña en su "Doctrinal de gentileza". 42

Sin embargo, en "Con pura malenconía", su respuesta, Román no respeta ni el patrón métrico (una quintilla seguida de una sextilla) ni el estilo retórico del texto de Montoro. El autor inicia el poema estableciendo la situación --"pues me distes menoscabo / en las trobas que yo hice / aquella dama"-- (lo que coincide con su tendencia a incluir en sus poemas la información contextual que los explica); y a partir de su segunda copla introduce una serie de amenazas. Entre ellas, reta al Ropero a que vuelva a su verdadero oficio:

Y por más haber placer, os haré por mis enmiendos, pues hablastes, tornar de nuevo a coser $\mathrm{y}$ volver a los remiendos que dejastes.

Y también combina motes descubiertos con motes de linaje:

Vos, hinchado con pajuela, gordo, lechón de molino, ansarón, criado a leche y verzuela, tonel entero de vino, vinagrón; melcochero, pasafrío,

${ }^{42}$ Ludueña se movía en los círculos poéticos y espacios literarios donde se transmite la obra de Montoro. Aunque su producción no es muy copiosa, intercambia "El que pide gran señor" y "Como el buen rubí” con Gómez Manrique (1885, II: p. 201), en 1468 escribe la "Descomunión de amores", y le dedica a Isabel la Católica su "Doctrinal de gentileza". Los dos últimos textos se hallan en los códices LB1 (200, ff. 69r-70v) y MP2 (33, ff. 82r96r), donde también figura un número considerable de poemas del Ropero. 


\begin{abstract}
vil escopido marrano
huy haví

del todo punto judío

circundado por la mano

del rabí. ${ }^{43}$
\end{abstract}

El Comendador no sólo ataca al Ropero por su apariencia física y origen judío, sino que combina los motes de linaje con los de oficio creando un agresivo chiste de índole sexual:

Yo querría sin debate,

Antón, salvaros la rixa

en este trote,

y pues sois buen alfayate,

que fagáis a vuestra pixa

un capirote. ${ }^{44}$

Montoro responde entonces con el agresivo "Pobre de sabiduría"; pero en su primera copla deja claro que al salir fuera del ámbito de la gentileza, Román se merece el mote "rico de grosería". ${ }^{45}$ El Ropero se mantiene aquí dentro de los

43Para un análisis de este poema dentro de los parámetros de la literatura del carnaval, Vid. De Lope, "Le grotesque dans la représentation du converso: signification d'une

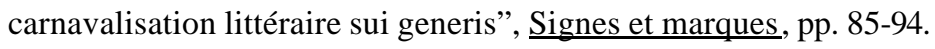

${ }^{44} \mathrm{El}$ vocablo capirote, que constituye un término clave para la caracterización del judío circunciso, ya figura como un motivo completamente codificado en las "Coplas del Provincial” (Ciceri 1989, pp. 442-443. Vid. J. Battesti-Pellegrin y M. de Lope 1993, pp. 4849).

${ }^{45}$ Es importante señalar que el mismo epíteto es utilizado varias veces por Ludueña en su "Doctrinal". Por ejemplo, al reprehender la manera de vestir de los cortesanos, escribe: "Y conviene berlo todo / el que quisiere salir / del hoyo de grosería" (MP2, fol. 70r en Labrador et al., 1986, p. 100). 
preceptos de la tradición: calca las rimas y el metro del texto al cual responde (sextillas de pie quebrado), utiliza motes descubiertos, anima a su contrincante a que escape de la ciudad ("No, por Dios, os lo levanto; / si no queréis destroiros / trasmontad") y alude a su origen árabe a través de una lítotes ("Vuestra madre no será / menos cristiana que mora"). Tras una violenta mención a su relación sexual con la progenitora de Román,

¡Muerte rabiosa os mate!

Tres libras y más de xixa, y almodrote, tengo para dar combate a vuestra madre, la golomixa, con mi garrote,

el Ropero cierra su poema con una gran concentración de apodos:

Establo muy testinado, todo de bestias inmundo hurta sillas;

reyes y grandes destado hacen, daquesto que fundo maravillas. A vos, bellaco, borrachón, dondes la vileza toda de mal sino, traen vos por un zanfón, quien os alaba os enloda, por indino.

Entonces el Comendador crea "Antón parias sin arrisco", un fascinante texto vejatorio donde, tras anunciar su reacción ("porque sto tan basilisco / que de 
verme moriréys", ${ }^{46}$ despliega su maestría de las galas del trobar a través de una serie de juegos de iteración fónica:

Trobar en ser carnicero

como la ley ordeno

trobar en comer carnero

degollado caral dio

qual vuestro padre comio

Trobar no comer tocino

pues la ley os lo vieda

trobar dezir sobrel vino

vuestra santa baraha

como aquel que la sabra

Trobar en cara muy leda

el dia ques de costumbre

y nunca tocar moneda

ni menos llegar a la lumbre

con reposo y mansedumbre.

46El texto sólo figura en 11CG-994, ff. 227r-229r, Dutton, 1991, V: pp. 523-525. 
Tras recorrer las costumbres alimenticias y los rituales judíos, Román se centra en el oficio al que debe dedicarse el Ropero:
trobad en bien conoscer
buena aguja y buen dedal
Trobar cantar con gritillo
vos sentado en vuestras gradas
y menudillo el puntillo
dando veynte cabeçadas
al echar de las puntadas.

Entre los vituperios incluidos, Román incluye una interesante referencia a los gustos de los rústicos de la época ("trobar en hacer carapuça / de secientas mil colores / y venderla a los pastores"). ${ }^{47} \mathrm{Al}$ cerrar, los últimos versos del poema recapitulan lo que se ha repetido incesantemente a lo largo de sus diecinueve novenas:

$$
\begin{aligned}
& \text { tomareys mi buen consejo } \\
& \text { que dexes este trobar } \\
& \text { y que os vays a remendar. }
\end{aligned}
$$

En su réplica, "Por vuestras letras pasé", Montoro declara abiertamente su derrota:

Por vuestras letras pasé, adornadas con virtud, dinas de creer sin ver, y cuando bien las tenté, denvidia pura non pud

\footnotetext{
${ }^{47}$ Hay que recordar que la idealización de este grupo social no se llevaría a cabo hasta en siglo siguiente.
} 
acabarlas de leer.

Y tras elogiar varias veces a Román, acepta humildemente su consejo:

así quespejo de nos,

pues mostráis tales razones,

yo voto al cuerpo de Dios,

que nunca delante vos

salga de coser jubones.

El contenido de este texto, que menciona reiteradas veces el valor del adversario y la poca pericia del yo poético, contrasta con su inusitada estructura métrica, ya que sus cuatro coplas repiten los patrones de cada uno de los textos de la contienda: una sextilla simple (primer texto de Montoro), una sextilla con pie quebrado (primer ataque de Román), y una novena compuesta de una redondilla de rimas abrazadas y una quintilla (último ataque del segundo). A pesar de la capitulación (que sólo se lleva a cabo en la superficie), el Ropero ha vuelto a la carga con un novedoso e irónico reto en el que hace gala de su agudeza e ingenio.

El Comendador acepta el nuevo desafío y vuelve a agredir a Montoro en "RecordAntón que dormís", un fascinante texto hiperbólico donde, además de motejarlo por su aspecto físico ("vos, figura de baúl") y subrayar su procedencia judía ("aunque agora sois Antón / primero fuistes Saúl"), intenta describirlo a través de una hipérbole desmembradora donde utiliza, de referencia, todo el territorio nordafricano:

RecordAntón que dormís:

¿sois las islas de Guinea

o las momias dAlanquís

o la tierra de Judea, 
con su cuento de rabís.

Este poema que incluye desde las Azores y las Canarias, hasta Mauritania, Egipto y Judea, se inscribe dentro de la profusión y exceso característico de la literatura del carnaval. Montoro entonces redacta la réplica, "Pecador dellos venís" y la contienda no termina, sino que aún se intercambian cuatro textos injuriosos adicionales.

Para concluir, en la doble recuesta en cuyos ejes se hallan Juan de Valladolid y el Comendador Román de un lado, y Montoro del otro, puede leerse una misma actitud por parte del sastre remendón: ingenioso, irónico y defensivo cuando se enfrenta a una persona de rango superior; satírico y mordaz cuando el rival pertenece a una condición análoga a la suya. En "Vuestras letras pasé", el poeta menestral combina la ironía, el virtuosismo formal y la gracia conceptual, y produce un mensaje doble cuyo fondo anula lo que establece en su superficie. El dominio de la poesía --ejercicio reservado para los hombres discretos que "conocían las artes sutiles, poseían un elevado entendimiento y, a través del estudio, habían accedido a altas invenciones y sano juicio"--, ${ }^{48}$ había adquirido tal estima en la sociedad cortesano-caballeresca del cuatrocientos, que era capaz tanto de avalar la presencia de un ropavejero converso en los círculos palaciegos, como de protegerlo --tras sus insolencias-- hacia personajes de la talla del Comendador Román. El Ropero se ampara en esta novedosa situación y su recuesta con el contino de los Reyes Católicos recrea magníficamente la flexibilidad de una sociedad que, aunque aún funciona dentro de los parámetros de un imaginario jerárquico, se ha hecho inusitadamente permeable para todo el que maneja sus códigos culturales.

48José Labrador Herraiz, "Las preocupaciones doctrinales de los poetas del Cancionero de

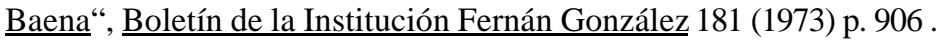


Frente a esta sorprendente situación, los agresivos motes de linaje de que se vale en su recuesta con Juan de Valladolid muestran las estrategias de ascenso social y sobreviencia de un converso que pertenece a la nueva clase mercantil y vive en una sociedad en la que se está imponiendo una ideología homogénea y monolítica. Tanto sus poemas como las respuestas que suscita de Valladolid recrean y reproducen los temores y las obsesiones de un público cortesano y cristiano viejo que se sentía cada vez más amenazada por la población neocristiana y las nuevas formas económicas que ésta representa, y se liberaba a través de la risa.

A pesar de las marcadas diferencias entre sus recuestas con Valladolid y Román, en ambos intercambios poéticos Montoro repite una y otra vez la misma acusación: la copla no es vuestra, devolvedla a su verdadero autor. A nivel profundo la denuncia de robo puede remitir a la apropiación de una personalidad enteramente cristiana (por un lado de Román, quien es parcialmente árabe, y por el otro de Valladolid, quien a su vez es semi judío). Esta usurpación de una identidad no fragmentaria --o acusación de haberlo hecho-- resultaba cada vez más necesaria en una sociedad que quería borrar su pasado tricultural y afirmar una serie de valores monovalentes: un Estado, una cultura, una religión. En este sentido, Montoro, el único poeta de su época que afirmó abiertamente su origen judío y defendió frente a nobles y monarcas el valor de la población conversa, paradójicamente también se vio obligado a recrear el imaginario social excluyente que se impone a lo largo del siglo y ha de justificar la Bula de la Inquisición, la expulsión de los judíos y las persecuciones de la población mozárabe de los siglos siguientes. 